Article

\title{
Sexual Motivations and Ideals Distinguish Sexual Identities within the Self-Concept: A Multidimensional Scaling Analysis
}

\author{
Celeste Sangiorgio $^{1}$, Warren A. Reich ${ }^{1}{ }_{*}$, Andrea C. Vial ${ }^{2}$ and Mirko Savone ${ }^{3}$ \\ 1 Department of Psychology, Hunter College of the City University of New York, 695 Park Avenue, \\ New York, NY 10065, USA; E-Mail: CSangior@hunter.cuny.edu \\ 2 Department of Psychology, Yale University, 2 Hillhouse Ave., New Haven, CT 06520, USA; \\ E-Mail: Andrea.vial@yale.edu \\ 3 Department of Pediatrics, Columbia University Medical Center, 630 W. $168^{\text {th }}$ Street, New York, \\ NY 10032, USA; E-Mail: Ms4750@columbia.edu \\ * Author to whom correspondence should be addressed; E-Mail: Wreich@hunter.cuny.edu; \\ Tel.: +1-646-386-3828; Fax: +1-212-397-0985.
}

Received: 2 December 2013; in revised form: 5 April 2014 / Accepted: 11 April 2014 /

Published: 22 April 2014

\begin{abstract}
Many studies explore when and how young people make sexual choices but few empirical investigations link their sexual motivations with their inner conceptions about their sexual identities. We used multidimensional scaling (MDS) analysis to connect young adult participants' $(\mathrm{N}=128)$ self-descriptions of twelve identities to their sexual motivations and ideals. Identities clustered along two semantically distinct dimensions: Dimension 1 was anchored by family identities on one side and non-family identities on the other; Dimension 2 was anchored on one side by friend/romantic relationships and achievement-based social identities on the other. Those who cited intimacy (e.g., sex as an expression of love) and enhancement (e.g., gratification; to feel good) sexual motivations were more likely to describe their sexual identities and gender identities as distinct from other identities, especially for women. Idealizing physically passionate relationships was positively linked to a higher distinction between sexual and non-sexual identities, and between gender and personal identities and family identities. The mental structuring of identities may inform sexual relationship motives, ideals, and expectations.
\end{abstract}


Keywords: Multidimensional Scaling Analysis; semantic space; identity; sexual motivation; idealization; intimacy; dissimilarity; physical attraction

\section{Sexual Motivations and Ideals Distinguish Sexual Identities within the Self-Concept: A Multidimensional Scaling Analysis}

Young adults vary considerably in the subjective meaning they derive from sexual activity and intimate relationships [1-3]. In Erik Erikson's psychosocial stage model, sexual exploratory behaviors beginning at adolescence belong to the Intimacy vs. Isolation stage, in which individuals test their unique ability to link with others in a mature and intimate way [4]. In the years following adolescence, individuals typically develop intimate relationships when they share their sexual and romantic feelings with others; they become increasingly isolated if they fail to do so and, thereby, shun their personal potential to develop sexual and romantic relationships [5]. In the present study we frame the construct of identity as a set of cognitive self-schemas, or domain-specific, associative networks of self-beliefs that reflect demands for situation-specific behaviors [6,7]. Self-schema models propose that culturally-specific mores and personal attitudes develop socially-defined, internalized identities that are activated in sexual contexts in order to dictate personal behaviors and interpret others' behaviors [8-11]. Our focus is on the sexual self, specifically the degree to which it is semantically distinct from other identities in the multifaceted self-system.

\subsection{Psychological Differentiation of Sexual and Non-sexual Relationships}

Contemporary models of psychosocial development operationalize the Intimacy vs. Isolation stage in terms of differentiation, defined as the extent to which an individual seeks out sexual relationships with the intention of exploring a personal sexual identity distinct from other familial and interpersonal relationships [12-14]. Differentiation therefore assumes that adolescents' sexual behaviors are motivated by the goal of testing and constructing idealized sexual interactions. It also assumes that sexually motivated individuals are aware of domain-specific behaviors (e.g., sexual interactions vs. familial interactions) and have a growing sense of the differences among the ways they should and could act in different social scenes. Most studies ask participants to imagine and report their thought processes in recent and/or imagined sexual activities [15], ask participants to explain reasons for engaging in recent sexual activities [2], or ask partners to complete measures of attachment style $[12,16,17]$.

In most studies of sexual behavior, individuals are asked to report the reasons they typically engage in sexual activities or are asked to explain their motivations for recent sexual activity $[1,18,19]$. Studies on sexual motivation have found that individuals' reasons for sexual activity tend to fall into six types of sexual motivation styles: enhancement, or sexual pleasure; intimacy, or bonding with one's partner; peer pressure, fulfilling expectations of one's peers; self-affirmation, or sex as a pathway to confirm one's beliefs about oneself; coping, or sex to reduce negative affect; and partner approval, or sex because of pressure from one's partner [1,2]. Investigations into sexual schemas as internalized norms [20,21], have described two types of sexual relationship idealization: relational idealization (the 
desire to seek out sexually intimate relationships that are strong in emotional investment) and passionate idealization (the desire to seek out passionate and physically expressive sexual relationships) [20]. Those who score highly on relational idealization tend to cite commitment and emotional reasons for engaging in sexual activities, rather than personal attraction reasons [8,20], and those who score highly on passionate idealization state that physical attraction and exploration tend to motivate their sexual activity.

Attachment-theoretical studies assess the qualities of dyadic bonds: securely attached partners are comfortable within their relationships, maintain individual autonomy, and have appropriate reactions to each other; anxiously attached partners are overprotective and hyper-vigilant; avoidant partners avoid sharing intimate details with their partners and tend to avoid developing deep relationships. These investigations have linked secure partner attachment with greater sexual satisfaction and cohesion, anxious attachment with highly fluctuating but interdependent sexual and relationship quality reports, and avoidant attachment with more one-night stands and diminished reports either of positive or negative sexual quality [15-17]. These studies do not describe a key component of Identity vs. Intimacy: the differentiation, or distinctions, individuals uniquely experience among self-beliefs about their sexual identity and beliefs about other relationships.

\subsection{The Current Study}

Many studies that analyze the relationship between sexual decision-making and the attitudes that young people hold $[2,15,17]$. However, there are few studies on subjective sexual identity, instead of reactions post-activity (however, see $[1,18,19]$ ). The current study seeks to add to existing research about sexual self-beliefs and differentiation, or distinctions among identities, by investigating the relationships among sexual motivations, relationship idealization, and the structural distinction of the sexual identity within the self. To this end, we use multidimensional scaling (MDS) analysis, which is well-suited to studying the distinction between sexual and non-sexual identities. MDS creates a cognitive "map" of identities based on participants' sets of self-descriptions. In psychological research, MDS is typically used to establish latent structural relationships among types of existing categories [20-22].

As there is relatively little research in this area, our investigations are exploratory. We pose the following research questions: (1) What is the structural relationship between the sexual self and other identities within the semantic space of the self? (2) Is this structural property correlated with psychosocial outcomes, namely, sexual motivations and sexual relationship idealization?

\section{Method}

\subsection{Participants}

One hundred twenty-eight ( 81 female) students in a large, urban university participated in a study about sexual attitudes and identity for course credit. All participants in our sample were between the ages of 18-21, though the majority of participants were either 18 or 19 (75.8\%). Only nine of our participants did not self-describe as heterosexual (7\%); seven reported that they were homosexual or bisexual, one reported other, and one participant chose not to disclose. Our sample was highly 
ethnically diverse: the majority of participants were white (33.3\%), followed by Asian (29.3\%), Latino (20.2\%), and African American (13.1\%). The remaining 4.1\% of participants either selected more than one ethnicity or chose not to disclose.

\subsection{Materials}

Participants reported to the laboratory for a session in which they were given pen-and-paper tasks. Materials were arranged into two sections and counterbalanced: the self-descriptive task from which the multidimensional scaling analysis variables were derived; the Ideal Sexual Self Scale [8] and the Sex Motives Scale [1] were given in another section ${ }^{1}$.

\subsection{Sexual Experience Variables}

Three of the items asked participants to disclose sexual experience information in yes or no format. Two items asked participants whether they currently were or had ever been in an exclusive sexual relationship (defined as a mutual agreement by both partners to not have sex with others). Another item asked if participants had ever had sexual intercourse with a casual partner (defined as someone who they were not in an exclusive sexual relationship with). We used these three items to create a binary variable that identified the 99 participants with sexual experience, indicated by a "yes" to at least one of these questions.

\subsection{Sexual Motivation and Idealization Variables}

Idealization scores were derived from the Ideal Sexual Self Scale [8] via a five-point Likert scale from 1 (Very Descriptive of Me) to 5 (Not at all descriptive of Me). Relational idealization was derived from as the mean rating of three items (e.g., "I would need to know someone really well before I had sex with them"; I could enjoy sex with someone for whom I felt no real affection" [reverse scored]). Passionate idealization was the mean rating of six items (e.g., "I could get so physically aroused I couldn't stop"; "Ideally, I would have strong sexual urges"). Reliabilities for the relational and passionate idealization subscales were high, $\alpha=0.89$ and $\alpha=0.75$, respectively.

Six sexual motivation subscales were generated through the Sex Motives Scale [1], which asks participants how often they engage in sexual activities for specific reasons on a 5-point Likert scale from 1 (Almost never/never) to 5 (Almost always/always). The six subscales are: intimacy (sex to express feelings of closeness to or affection towards one's partner, $\alpha=0.95$ ), enhancement subscale (i.e., sex for sexual gratification, $\alpha=0.93$ ), "coping" (i.e., sex to reduce feelings of stress, $\alpha=0.92$ ), "partner approval" (i.e., sex to please or appease a partner, $\alpha=0.89$ ), "self-affirmation" (i.e., sex as a means to create positive feelings towards oneself, $\alpha=0.93$ ), and "peer pressure" (i.e., sex because it is expected by one's peers, $\alpha=0.94$ ).

1 Other materials were given but are not reported here because they are not relevant to the current analyses. 


\subsection{Multidimensional Scaling Analysis}

Participants described 12 randomly-ordered personal and social identities using a pre-defined list of 50 traits: characteristic behaviors, feelings, and mood states associated with a given identity (e.g., friendly, caring, romantic, shame, don't care). Of the 12 identities, one directly referenced participants sexual identity ("my sexual self"), one measured potentially sexual intimate relationships ("myself with my romantic partner"), and another measured participants" gender identity ("myself as a man/woman"). The trait list (see Appendix) was generated in part by previous sexual schema studies [21,23] and from trait lists used in previous studies [24]. Participants were told that they could select however many or few of the 50 traits that they felt applied to each role.

We used this data to create a 12 by 50 binary matrix for each participant in which rows represented identities and columns represented traits. If a participant applied a given trait to an identity, then a 1 was input into the corresponding cell, 0 otherwise. These matrices were then transformed into participant-specific proximity matrices using the squared Euclidean dissimilarity values between identities across traits. The resulting proximity matrices were 12 by 12 identity by identity matrices, one for each participant, where cell values represented the semantic distance between two identities based on shared and non-shared traits. A relatively large value between two identities reflects a large mental discrepancy between them; literally, they differ in their trait profiles.

We ran a three-way MDS analysis on the set of identity by identity distance matrices described above. Three-way MDS produces an N-dimensional map that represents the dispersion and dimensionality among identities both for the entire sample (the "group space"), and a separate output that indicates the extent to which the underlying dimensions are weighted in each individual's set of self-descriptions [21,25]. The distinction of the sexual and relationship identities for each person is reflected by the dimension weights. Someone with a highly distinct sexual self would have a relatively large weight on a dimension anchored on one end in the group space by the sexual self.

\section{Results}

\subsection{MDS Semantic Space Map}

We ran the MDS analysis for our sample in two and three dimensions. The two-dimensional solution (shown in Figure 1) produced a stress (or badness-of-fit) value of $0.35, R^{2}=0.14$. The arrangement of identities was interpretable, however: dimension 1 (horizontal) anchored by family vs. personal identities and dimension 2 (vertical) was anchored by friend/romantic relationships vs. achievement-based social identities. The three-dimensional solution was not only less interpretable (the dimensions were anchored by friend vs. social identities, romantic and family identities vs. achievement-oriented identities, private and sexual self vs. family and religious identities), but also yielded only a small improvement in stress $(0.27)$ and $R^{2}(0.15)$. We then split the sample into two random groups and performed the MDS analysis separately on each. The structural locations of the identities (literally, their dimension 1 and dimension 2 coordinates) were more highly correlated across split samples for the two-dimensional solution $(r \mathrm{~s}=0.93$ and 0.57 for dimensions 1 and 2 , respectively) than they were for the three-dimensional solution ( $r \mathrm{~s}=0.58,0.44$, and 0.65 for dimensions 1 through 3). For these reasons we decided to use the two-dimensional model. 
Figure 1. Multidimensional semantic space across sample's identities.

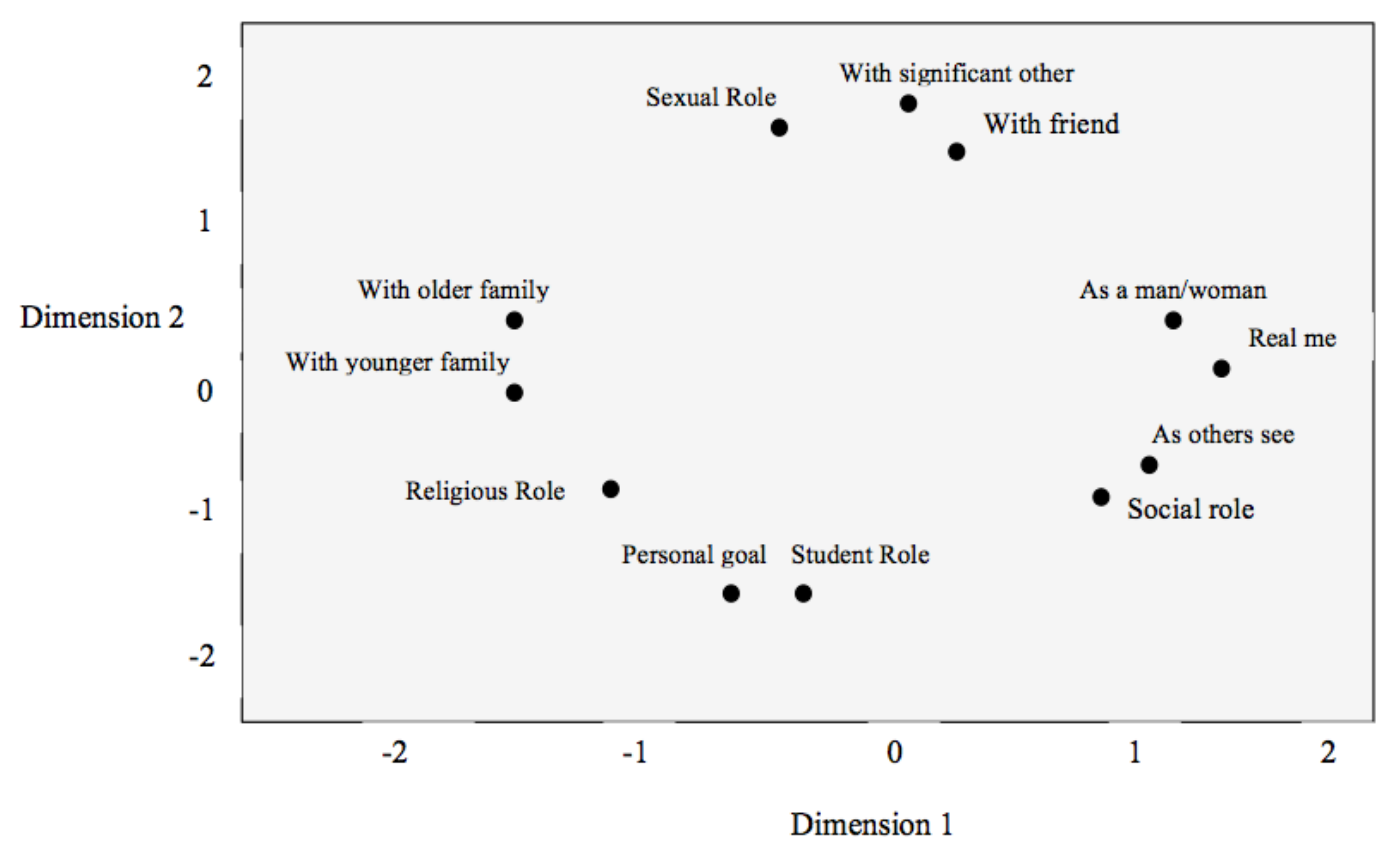

In the two-dimensional space, identities clustered in a circumplex pattern that offers a straightforward interpretation. Dimension 1 seemed to reflect a general distinction between private and gendered selves vs. family relationship selves. Dimension 2 appeared to distinguish romantic/intimate vs. achievement-based social identities. Three-way MDS also computes dimension weights for each participant, which reflect the importance or salience of a dimension in his or her self-descriptive data. Participant's dimension 1 and dimension 2 weights were highly correlated, $r=0.84, p<0.001$, suggesting that those with highly distinct personal identities also had highly distinct sexual and romantic relationship identities.

\subsection{Correlations among Sexual Motivations, Idealization, and Identity Distinction}

Passionate idealization was positively correlated with dimension 1 weight and with dimension 2 weight (see Tables 1 and 2) but relational idealization was not correlated with either dimension weight. We then split our sample by gender and found that the correlation was stronger for women than for men. A greater positive relationship was found among passion idealization and dimensional weights for women but a Fisher's z-test revealed that the correlations for each gender were not significantly different, $z=0.67, p=0.50$ and $z=0.38, p=0.70$ for dimensions 1 and 2 , respectively.

We computed correlations between sexual motivation and dimension weights for sexually experienced participants only $(n=99)$. There was a marginal positive trend between enhancement sexual motivation and dimension 1 weights. Correlations split by gender revealed that intimacy motivations were significantly correlated with both dimensional weights for female but not male participants (see Tables 3 and 4). A Fisher's z-test showed that the correlation was significantly stronger for women than for men on both dimensions, $z=2.61, p<0.05$ and $z=1.9, p<0.05$, respectively. Enhancement motivation had a positive relationship trend with dimension 2 weights, and 
a Fisher's-z test confirmed that while the relationship was stronger for males, there was no gender difference in this correlation, $z=0.91, p=0.36$.

Table 1. Correlations among relationship idealization variables and dimension weights.

\begin{tabular}{ccc}
\hline & $\begin{array}{c}\text { Passion } \\
\text { Idealization }\end{array}$ & $\begin{array}{c}\text { Relational } \\
\text { Idealization }\end{array}$ \\
\hline Dimension 1 weight & $0.25 *$ & -0.12 \\
Dimension 2 weight & $0.21 *$ & -0.03 \\
\hline \multicolumn{3}{c}{ Note: $* p<.05, * * p<.001}$.
\end{tabular}

Table 2. Correlations among relationship idealization variables and dimension weights by gender.

\begin{tabular}{clcc}
\hline & & $\begin{array}{c}\text { Passion } \\
\text { Idealization }\end{array}$ & $\begin{array}{c}\text { Relational } \\
\text { Idealization }\end{array}$ \\
\hline \multirow{2}{*}{ Female } & Dimension 1 weight & $0.30 * *$ & -0.12 \\
& Dimension 2 weight & $0.25 *$ & -0.02 \\
Male & Dimension 1 weight & 0.18 & -0.23 \\
& Dimension 2 weight & 0.15 & -0.08 \\
\hline \multicolumn{3}{c}{ Note: $* p<.05, * * p<.001}$.
\end{tabular}

Table 3. Correlations among sex motives and dimensional weights for sexually experienced participants.

\begin{tabular}{ccccccc}
\hline & Intimacy & $\begin{array}{c}\text { Enhance- } \\
\text { ment }\end{array}$ & $\begin{array}{c}\text { Self- } \\
\text { Affirmation }\end{array}$ & Coping & $\begin{array}{c}\text { Peer } \\
\text { Pressure }\end{array}$ & $\begin{array}{c}\text { Partner } \\
\text { Approval }\end{array}$ \\
\hline Dimension 1 weight & 0.07 & $0.16^{+}$ & -0.07 & -0.02 & -0.10 & -0.06 \\
Dimension 2 weight & 0.11 & 0.14 & -0.06 & 0.01 & -0.12 & 0.08 \\
\hline \multicolumn{7}{c}{ Note: ${ }^{*} p<0.05,{ }^{* *} p<0.001,{ }^{+} p<0.09}$. \\
\end{tabular}

Table 4. Correlations among sex motives and dimensional weight for sexually experienced participants, split by gender.

\begin{tabular}{llcccccc}
\hline & & Intimacy & Enhancement & $\begin{array}{c}\text { Self- } \\
\text { Affirmation }\end{array}$ & Coping & $\begin{array}{c}\text { Peer } \\
\text { Pressure }\end{array}$ & $\begin{array}{c}\text { Partner } \\
\text { Approval }\end{array}$ \\
\hline \multirow{2}{*}{ Female } & Dimension 1 weight & $0.24^{*}$ & $0.24 *$ & 0.10 & 0.15 & 0.14 & -0.14 \\
& Dimension 2 weight & $0.23^{*}$ & $0.20^{+}$ & 0.07 & 0.15 & 0.08 & 0.05 \\
\multirow{2}{*}{ Male } & Dimension 1 weight & $-0.25^{+}$ & 0.07 & -0.22 & -0.21 & -0.23 & -0.27 \\
& Dimension 2 weight & -0.13 & 0.05 & -0.18 & -0.24 & -0.24 & $0.22^{+}$ \\
\hline
\end{tabular}
Note: ${ }^{*} p<0.05,{ }^{* *} p<0.001,{ }^{+} p<0.09$.

Splitting the sample by gender revealed that enhancement motivation was significantly and positively related to dimension 1 weights for females, and several marginally significant trends among sexual motivation scores and dimensional weights. Higher intimacy motivation had a negative relationship with male participants dimension 1 weights, as did partner approval motivations. 


\section{Discussion and Conclusions}

\subsection{Distinction of the Sexual Identity within the Self-Structure}

Individuals clearly vary in their subjective experiences of sexual identity. For young adults, this is part of the process of constructing a new and distinct sexual identity. There are several theories about why this occurs, but we are aware of no prior research that has directly assessed the structural position of the sexual self in relation to other identities, and explicitly related structural variables to sexual motivations and relationship idealization styles.

The circumplex pattern of identities placed sexual identities and gender identities apart for achievement- and family based identities, and so our young adult participants generally tended to see sexual and gender identities as distinct aspects of their overall conceptions of themselves.

\subsection{Psychosocial Correlates of a Distinct Identities}

Studies of sexual behaviors and perceptions in young adults tend to derive statements about subjective sexual experience through sexual motivations, differentiation, and relationship idealization, but do not directly assess identity structure [26,27]. The present study elaborated upon a sample-specific, parsimonious map in which sexual differentiation can be framed.

We found that while passionate idealization was positively correlated with both dimension weights. Participants (especially women) who psychologically magnified the distinction between their sexual and gender identities vs. their achievement-based social identities and family relationship identities were more likely to describe their ideal sexual relationship as being highly physically passionate. It is possible that the gender differences we found were influenced by gender norms and expectations that affected participant responses; gender norms and internalized scripts have been observed to affect participants' perceptions in the past [28-31]. Our study is cross-sectional, so no statements about directionality can be made. Future investigations should study changes in identity salience and relationship idealization styles at several times.

Our sexual motivation findings varied by gender. Women who reported intimacy motivations for sexual activity were more likely to describe sexual and gender identities as distinct from familial identities and achievement-based social identities, respectively. While non-significant, there was a reversed trend in male participants' data: viewing sexual identities and achievement-based social identities as less distinct was linked to intimacy scores. Although stronger in women, there was a trend where sex for means of sexual gratification was associated with larger distinction among both dimensions; this trend was less significant for distinctions among private/gender identity and family identities. In male participants, engaging in sex due to perceived partner demands was negatively associated with distinction between sexual identities and family identities.

Our findings contribute to a rich literature on gendered perceptions of sexual self-beliefs $[1,8,18,19,32-34]$ and pose questions for future analyses. The unique relationship observed between gender identity and intimacy motivations may be influenced by differences in the speed of sexual development in males and female; it could also be due to gendered internalized norms and self-beliefs $[18,19,33]$. It is outside of the scope of the current study to explain why gender was related to differences in seeking out sexual relationships to explore intimacy with a partner. However, the 
finding encourages that future studies explore gender differences, sexual identity, and sexual motivations in greater depth. These studies would benefit by adding behavioral reports in their methods so that the links among subjective sexual self-beliefs and sexual activity can be explored.

Future studies could benefit from incorporating measures of partner attachment style [35] differentiation level [14,36] and psychosocial development [37] into investigations of the sexual identity's content and placement within the self-structure [19,38,39]. Exploring the content of sexual identity's self-descriptions and individuals' relationship status may also lend valuable information to the salience of a unique sexual identity within the self-structure. Future investigations into the sexual identity's structural location and partner attachment should consider including data from sexually active couples as this area has been investigated from a motivational perspective but not from a self-structure one. In general, the addition of self-structure analyses to sexual development has the potential to enhance our understanding and explain a hidden depth of sexual self-beliefs. Understanding sexual self-beliefs may help researchers orient health interventions towards safer sex by creating realistic messages that affect young adults attitudes about condom usage.

\section{Author Contributions}

Andrea C. Vial and Warren A. Reich conceptualized and designed this study. Vial and Celeste Sangiorgio supervised data collection, cleaning, and initial descriptive analyses. Reich and Sangiorgio conceptualized and performed the major statistical analyses. Sangiorgio, Vial, Reich, and Mirko Savone all contributed to writing the manuscript.

Appendix. Trait List.

\begin{tabular}{|llll|}
\hline Aggressive & Excited & Motivated & Romantic \\
Angry & Experienced & Not physically attractive & Sad \\
Arousable & Feeling & Open minded & Selfish \\
Assertive & Flashy & Optimistic & Sexual \\
Broad-minded & Friendly & Outgoing & Shame \\
Caring & Guilty & Outspoken & Shy \\
Confident & Happy & Passionate & Straightforward \\
Conservative & Honest & Physically attractive & Tired \\
Dependable & Inexperienced & Physically fit & Trusting \\
Direct & Insecure & Promiscuous & Vulnerable \\
Distant & Intelligent & Protective & Worried \\
Don't care & Lazy & Respect & \\
Embarrassed & Loving & Revealing & \\
\hline
\end{tabular}

Note: Trait tasks were completed for each of the following randomly ordered 12 identities: my privately held view of myself, as others see me, me in a social role, myself with an older family member, myself with a younger family member, myself with a friend, myself with my significant other, myself in a spiritual or religious role, myself as a student, myself in my most important personal goal, myself as a man/women, my sexual self. 


\section{Conflicts of Interest}

The authors declare no conflict of interest.

\section{References}

1. Cooper, M. Lynne, Cheryl M. Shapiro, and Anne M. Powers. "Motivations for sex and risky sexual behavior among adolescents and young adults: A functional perspective." Journal of Personality and Social Psychology 75, no. 6 (1998): 1528-58.

2. Dawson, Laura H., Mei-Chiung Shih, Carl de Moor, and Lydia Shrier. "Reasons why adolescents and young adults have sex: Associations with psychological characteristics and sexual behavior." Journal of Sex Research 45, no. 3 (2008): 225-32.

3. Rosen, Raymond C., and Gloria A. Bachmann. "Sexual well-being, happiness, and satisfaction, in women: The case for a new conceptual paradigm." Journal of Sex \& Marital Therapy 34, no. 4 (2008): 291-97.

4. Erikson, Erik Homburger. Identity and the Life Cycle. New York: WW Norton \& Company, 1980, vol. 1.

5. Erikson, Erik Homburger. "The problem of ego identity." Journal of the American Psychoanalytic Association 4 (1956): 56-121.

6. William, James. The Principles of Psychology. Cambridge, MA: Harvard University Press, 1890.

7. Woolfolk, Robert L., James Novalany, Michael A. Gara, Lesley A. Allen, and Monica Polino. "Self-complexity, self-evaluation, and depression: An examination of form and content within the self-schema." Journal of Personality and Social Psychology 68, no. 6 (1995): 1108-20.

8. Hynie, Michaela, John E. Lydon, Sylvana Cote, and Seth Wiener. "Relational sexual scripts and women's condom use: The importance of internalized norms." Journal of Sex Research 35, no. 4 (1998): 370-80.

9. Simon, William, and John H. Gagnon. "Sexual scripts: Permanence and change." Archives of sexual Behavior 15, no. 2 (1986): 97-120.

10. Rosenberg, Seymour. "Multiplicity of selves." In Self and Identity: Fundamental Issues. Edited by Richard D. Ashmore and Lee Jussim. New York: Oxford University Press, 1997, vol. 1, pp. 23-45.

11. Ogilvie, Daniel M., and Richard D. Ashmore. "Self-with-other representation as a unit of analysis in self-concept research.” In The Relational Self: Theoretical Convergences in Psychoanalysis and Social Psychology. Edited by Rebecca C. Curtis. New York: Guilford Press, 1991, pp. 282-315.

12. Jenkins, Steve M., Walter C. Buboltz, Jr., Jonathan P. Schwartz, and Patrick Johnson. "Differentiation of self and psychosocial development." Contemporary Family Therapy 27, no. 2 (2005): 251-61.

13. Bowen, Murray. Family Therapy in Clinical Practice. Lanham: Jason Aronson, Inc., 1993.

14. Skowron, Elizabeth A., and Thomas A. Schmitt. "Assessing interpersonal fusion: Reliability and validity of a new DSI fusion with others subscale." Journal of Marital and Family Therapy 29, no. 2 (2003): 209-22.

15. White, Kathleen M., Joseph C. Speisman, Doris Jackson, Scott Bartis, and Daryl Costos. "Intimacy maturity and its correlates in young married couples." Journal of Personality and Social Psychology 50, no. 1 (1986): 152-62. 
16. Birnbaum, Gurit E., Harry T. Reis, Mario Mikulincer, Omri Gillath, and Ayala Orpaz. "When sex is more than just sex: Attachment orientations, sexual experience, and relationship quality." Journal of Personality and Social Psychology 91, no. 5 (2006): 929-43.

17. Fraley, R. Chris, and Phillip R. Shaver. "Adult romantic attachment: Theoretical developments, emerging controversies, and unanswered questions." Review of General Psychology 4, no. 2 (2000): 132-54.

18. Hynie, Michaela, and John E. Lydon. "Sexual attitudes and contraceptive behavior revisited: Can there be too much of a good thing?" Journal of Sex Research 33, no. 2 (1996): 127-34.

19. Vial, Andrea C., and Warren A. Reich. "A hierarchical analysis the sexual self of college men and women.” Unpublished work, 2014.

20. Rusbult, Caryl E., and Isabella M. Zembrodt. "Responses to dissatisfaction in romantic involvements: A multidimensional scaling analysis." Journal of Experimental Social Psychology 19, no. 3 (1983): 274-93.

21. Viken, Richard J., Teresa A. Treat, Robert M. Nosofsky, Richard M. McFall, and Thomas J. Palmeri. "Modeling individual differences in perceptual and attentional processes related to bulimic symptoms." Journal of Abnormal Psychology 111, no. 4 (2002): 598-609.

22. Robinson, Sandra L., and Rebecca J. Bennett. "A typology of deviant workplace behaviors: A multidimensional scaling study.” Academy of Management Journal 38, no. 2 (1995): 555-72.

23. Andersen, Barbara L., and Jill M. Cyranowski. "Women's sexual self-schema." Journal of Personality and Social Psychology 67, no. 6 (1994): 1079-100.

24. Reich, Warren A., Ellen M. Kessel, and Frank J. Bernieri. "Life Satisfaction and the Self: Structure, Content, and Function.” Journal of Happiness Studies 14, no. 1 (2013): 293-308.

25. Carroll, J. Douglas, and Phipps Arabie. "Multidimensional scaling." In Measurement, Judgment, and Decision Making. Edited by Michael H. Birnbaum. San Diego: Academic Press, 1998, pp. 179-250.

26. Hazan, Cindy, and Debra Zeifman. "Sex and the psychological tether." In Advances in personal relationships: Attachment Processes in Adulthood. Edited by Kim Bartholomew and Daniel Perlman. London: Jessica Kingsley Publishers, 1994, vol. 5, pp. 151-78.

27. Shaver, Phillip R., and Mario Mikulincer. "A behavioral systems approach to romantic love relationships: Attachment, caregiving, and sex." In The New Psychology of Love. Edited by Robert J. Sternberg and Karin Weis. New Haven, CT: Yale University Press, 2006, pp. 35-64.

28. DeLamater, John. "Gender differences in sexual scenarios." In Females, Males, and Sexuality: Theories and Research. Binghamton: Vail-Ballou Press, 1987, pp. 127-39.

29. Ward, L. Monique, and Kimberly Friedman. "Using TV as a guide: Associations between television viewing and adolescents' sexual attitudes and behavior." Journal of Research on Adolescence 16, no. 1 (2006): 133-56.

30. Sanchez, Diana T., Corinne A. Moss-Racusin, Julie E. Phelan, and Jennifer Crocker. "Relationship contingency and sexual motivation in women: Implications for sexual satisfaction." Archives of Sexual Behavior 40, no. 1 (2011): 99-110.

31. Ballentine, Leslie Winfield, and Jennifer Paff Ogle. "The making and unmaking of body problems in Seventeen magazine, 1992-2003." Family and Consumer Sciences Research Journal 33, no. 4 (2005): 281-307. 
32. Carroll, Janell Lucille, Kari Doray Volk, and Janet Shibley Hyde. "Differences between males and females in motives for engaging in sexual intercourse." Archives of Sexual Behavior 14, no. 2 (1985): 131-39.

33. Leigh, Barbara Critchlow. "Reasons for having and avoiding sex: Gender, sexual orientation, and relationship to sexual behavior.” Journal of Sex Research 26, no. 2 (1989): 199-209.

34. Randolph, Bonnie J., and Barbara Winstead. "Sexual decision making and object relations theory." Archives of Sexual Behavior 17, no. 5 (1988): 389-409.

35. Brennan, Kelly A., Shey Wu, and Jennifer Loev. "Adult romantic attachment and individual differences in attitudes toward physical contact in the context of adult romantic relationships." In Attachment Theory and Close Relationships. Edited by Jeffry A. Simpson and W. Steven Rholes. New York: Guilford Press, 1998, pp. 394-428.

36. Brennan, Kelly A., Catherine L. Clark, and Phillip R. Shaver. "Self-report measurement of adult attachment." In Attachment Theory and Close Relationships. Edited by Jeffry A. Simpson and W. Steven Rholes. New York: Guilford Press, 1998, pp. 46-76.

37. Skowron, Elizabeth A., and Myrna L. Friedlander. "The Differentiation of Self Inventory: Development and initial validation." Journal of Counseling Psychology 45, no. 3 (1998): 235-46.

38. Hawley, Gwen A. MPD, Measures of Psychosocial Development: Professional Manual. Odessa: Psychological Assessment Resources, Inc., 1988.

39. Archer, Sally L., and Jeremy A. Grey. "The sexual domain of identity: Sexual statuses of identity in relation to psychosocial sexual health." Identity: An International Journal of Theory and Research 9, no. 1 (2009): 33-62.

(C) 2014 by the authors; licensee MDPI, Basel, Switzerland. This article is an open access article distributed under the terms and conditions of the Creative Commons Attribution license (http://creativecommons.org/licenses/by/3.0/). 